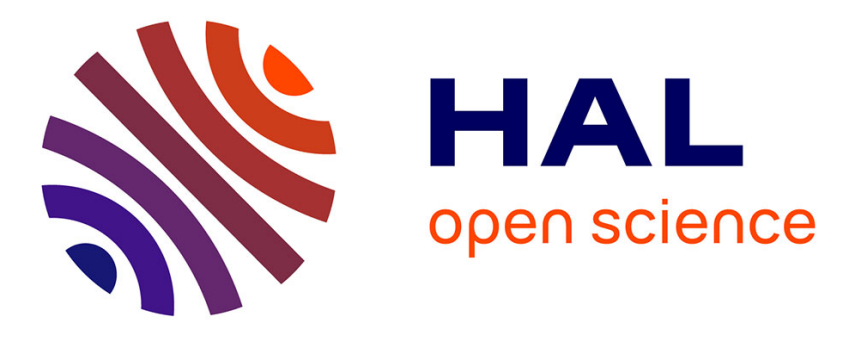

\title{
Shear flow curve in mixing systems-A simplified approach
}

Patrice Estellé, Christophe Lanos

\section{To cite this version:}

Patrice Estellé, Christophe Lanos. Shear flow curve in mixing systems-A simplified approach. Chemical Engineering Science, 2008, 63 (24), pp.5887-5890. 10.1016/j.ces.2008.08.019 . hal-00664456

\section{HAL Id: hal-00664456 https://hal.science/hal-00664456}

Submitted on 30 Jan 2012

HAL is a multi-disciplinary open access archive for the deposit and dissemination of scientific research documents, whether they are published or not. The documents may come from teaching and research institutions in France or abroad, or from public or private research centers.
L'archive ouverte pluridisciplinaire HAL, est destinée au dépôt et à la diffusion de documents scientifiques de niveau recherche, publiés ou non, émanant des établissements d'enseignement et de recherche français ou étrangers, des laboratoires publics ou privés. 


\title{
Shear flow curve in mixing systems - A simplified approach
}

\author{
Patrice Estellé *, Christophe Lanos \\ LGCGM, Département Matériaux et Thermo-Rhéologie, \\ Institut Universitaire Technologique, rue du Clos Courtel, BP 90422, \\ 35704 Rennes Cedex 7, France
}

\footnotetext{
* Author to whom correspondence should be addressed.

Electronic mail: patrice.estelle@univ-rennes1.fr

Tel: +33 (0) 23234200

Fax: +33 (0) 223234051
}

\section{Shorter communication}

\begin{abstract}
:
Rheological behaviour of fluids in mixing systems was studied using a simplified approach in shear rate calculation. The efficiency of this approach is investigated from Newtonian and non-Newtonian fluids, exploring also the geometry of mixing systems. Results are favourably compared with those obtained from previous published works. It is shown that this approach does not require the calculation of a virtual inner radius nor a priori assumption of the rheological behaviour of the fluid mixed.
\end{abstract}

Keywords: Mixer viscometry; shear rate; flow curve; rheology; shear-thinning fluids

\section{Introduction}

Industrial processes often require mixing, blending or dispersing systems to produce complex materials. These fluids are agitated in vessels from impellers of different geometries: anchors (Anne-Archard et al., 2006), helical ribbons (Choplin, 2000 ; Wang et al., 2000), small or large paddles (Thakur et al., 2004 ; Roos et al., 2006), scraper blades (Benkhelifa et al., 2008). Such systems are also used to evaluate or follow the rheological properties of the mixed material, in particular during phase change and thermal treatment. The main problem lies then on the calculation of the shear stress - shear rate relationship from the torque and rotational speed of mixing probe. Different methods have been developed for estimating the shear rate in the impeller zone (Steffe, 1992). From the power consumption method in laminar regime, the shear rate is related to the rotational velocity of the impeller with a mixer viscometer constant (Metzner and Otto, 1957). This constant is determined using the slope method or the 
matching viscosity method. The matching viscosity method needs at least two measurements and depends also on the type of shear thinning fluid used. A more recent method is based on the so-called Couette analogy (Choplin, 2000 ; Ait-Kadi et al., 2004) based on the approach developed by Bousmina et al. (1999). It consists in determining an internal radius of an equivalent virtual Couette geometry which gives for the same rotational velocity the same torque in mixer system. These methods, which have been largely improved, require however a priori assumption on the rheological behaviour of the fluid - generally assumed to be a power law fluid - as well as the calibration of the mixer system. The evaluation of the internal virtual radius of an equivalent Couette geometry is preliminary carried out with Newtonian fluids of known viscosity.

The aim of this paper is to show the efficiency of a recent procedure in processing the Couette rheometry data (Estellé et al. (2008 a ; 2008 b)) to compute the rotational shear flow data of fluids in mixing systems. The main objective is to overcome the limitations mentioned above. With this goal, we have considered previously published data of Newtonian and power law fluids in various mixing system. Influence of rheological behaviour and geometry system are also investigated. Before this, and to make more comprehensive this paper, some of the theoretical development reported in Estellé et al. (2008 a ; 2008 b) are briefly detailed in the next section.

\section{Theory}

The data of Couette viscometer are put in the form of a shear stress - shear rate relationships from a Bingham approximation in shear rate calculation. The shear rate of a Bingham fluid is a combination of two expressions following the flow condition in the annulus. It is related to the Couette geometry and set of torque velocity data $(\mathrm{M} ; \Omega)$ from the following equations, respectively when the cylindrical gap is partially sheared (eq. 1) and fully sheared (eq. 2).

$$
\begin{gathered}
\dot{\gamma}=2 M \frac{d \Omega}{d M} \\
\dot{\gamma}=2 \frac{M \frac{d \Omega}{d M}}{\left(1-\frac{R_{b}^{2}}{R_{c}^{2}}\right)}-\frac{\Omega \cdot-M \cdot \frac{d \Omega}{d M}}{\ln \left(\frac{R_{b}}{R_{c}}\right)}
\end{gathered}
$$

Where $R_{b}$, h and $R_{c}$ respectively denotes the radius and height of the inner cylinder, the radius of the cup.

In this procedure, the use of the maximization of the dissipation of energy allows discriminating between the partially sheared gap solution and the fully sheared one. 
This avoids a previous knowledge of the yield stress. So, from a series of increasing or decreasing rotational velocity $\Omega_{j}$, the shear rate is computed as well as the corresponding shear stress defined as $\tau=\frac{1}{2}\left(\tau_{j}+\tau_{j-1}\right)$, with $\tau_{j}=\frac{M_{j}}{2 \pi h R_{b}{ }^{2}}$. It should be noted that the derivative $\frac{d \Omega}{d M}$ is simply reduced to $\frac{\Omega_{j}-\Omega_{j-1}}{M_{j}-M_{j-1}}$.

This procedure was successfully tested for computing the shear flow curve of simulated and real fluids in Couette viscometer, independently of rheological behaviour and gap size (Estellé et al., 2008a). It was extended to vane geometry for Newtonian silicon oil, CMC (carboxymethylcellulose) solution and Carbopol as yield stress fluid. The results were found to agree well with those obtained using torsional geometry (Estellé et al., 2008b). It is presently used in the next section for processing the torque-velocity data of fluids obtained with mixing systems. Results are compared to those obtained from the currently used techniques in determining the shear flow curve in these systems.

\section{Experimental applications}

\subsection{Influence of rheological behaviour}

Recently, Guillemin et al. (2008) have developed a mixing-type rheometer called "RheoXF" which consists of a mixing complex impeller rotating in a large cylindrical cup. This mixing system was used to characterize the rheological properties of shear-thinning concentrated energetic suspensions of melt-cast intensive explosives. The procedure used by Guillemin et al. (2008) to process the torque - rotational velocity data is based on Couette analogy. To relate the shear stress and shear rate, the authors have considered a priori that energetic suspensions behave as a power law fluids. The constants of this system as well as the virtual internal radius of the equivalent Couette geometry have been obtained from measurements carried out with Newtonian fluids in both Couette (inner radius $R_{b}=18.96 \mathrm{~mm}$, outer radius $R_{c}$ $=19.99 \mathrm{~mm}$, height $\mathrm{h}=23.49 \mathrm{~mm}$ ) and mixing (upper radius $\mathrm{R}_{2}=14.26 \mathrm{~mm}$, lower radius $\mathrm{R}_{1}=19 \mathrm{~mm}$, height $\mathrm{H}=17.7 \mathrm{~mm}$ ) geometries. To improve the quality of calibration of their system, they have used several Newtonian materials with large viscosity scale. Guillemin et al. (2008) have finally determined a virtual inner radius of $17.17 \mathrm{~mm}$. Three of these fluids are here studied: an hydroxyl terminated polybutadene, called liquifex H, an urethane H-200-AT (Vosschemie) and a silicon oil Rhodorsil 47V500. Here, due to the geometry of the shearing spindle (see figure 1(a)), the radius considered in our calculation is the one which corresponds to the barycentre of the triangle of $\mathrm{H}$ in bottom and $\mathrm{R}_{1}-\mathrm{R}_{2}$ in height. Its value is $17.42 \mathrm{~mm}$. This is close to the virtual radius obtained by Guillemin et al. (2008). In Figure 2 we report the shear flow curves of Newtonian fluids obtained from our procedure in both Couette and 
mixing geometries. The performance of our approach is here estimated by computing the percentage deviation of the viscosity obtained with our approach from the true viscosity which was known from the Newtonian fluid used, as detailed in Table 1. It is shown that the curves of the two geometries agree well, and that the fluids behave as Newtonian materials. The maximum percentage deviation in calculated viscosity compared to the real value is less than $6.6 \%$ with the Couette geometry, respectively $14 \%$, with the mixing system.

The shear flow curves of energetic suspensions, respectively denoted E1 and E4 in Guillemin et al. (2008), are shown in Figure 3. As expected, these materials behave well as shearthinning fluids. Table 2 contains values of constitutive parameters fitted from the flow curves with a power law equation. Results given by Tables 2 show that the constitutive parameters evaluated by Guillemin et al. (2008) and those we obtain are in quite good agreement. The maximum deviation is $10.9 \%$ for the flow index value and $9.3 \%$ for the consistency value. It should be mentioned that Guillemin and co-workers (2008) have only used the Rheo-FX to evaluate the rheological properties of the suspensions. As a consequence, the constitutive parameters they obtain are considered being reference values.

It should be noted that with such materials, Newtonian and shear-thinning fluids, it was checked that only equation (2) is used in the calculation of shear rate, as the material is fully sheared within the gap.

\subsection{Influence of the geometry of mixing system}

Roos et al. (2006) have evaluated the capability of mixing systems for measuring the flow behaviour of fluid food containing fibres or particles. Three impellers have been used by these authors (see figure 1(b): a large six-bladed paddle (40mm in diameter and $60 \mathrm{~mm}$ in height), a small four-bladed paddle $(20 \mathrm{~mm}$ in diameter and $40 \mathrm{~mm}$ in height), and a helical ribbon (36mm in diameter and $40 \mathrm{~mm}$ in height). For all mixing systems, the fluid was sheared in a cup of $48.8 \mathrm{~mm}$ in diameter. For more experimental details, the reader is referred to Roos et al. (2006). As in the previous section, the authors have exploited the mixing system from Couette analogy, considering also a power law constitutive equation. In Figure 4, we report the shear flow curves of a fruit preparation of Raspberry which contains hard particles of $2 \mathrm{~mm}$ in averaged diameter. The black symbols are obtained by Roos et al. (2006). The open symbols correspond to the flow curves determined with our procedure using the torque velocity data obtained with the three impellers. It is shown that appropriate flow curves are recovered, independently of mixing systems. Moreover, the results compare well with the curves obtained by Roos et al. (2006). With small and large paddles, we have considered the real diameters of the probes for the determination of the shear flow curves. These values are close to the virtual diameters, respectively $19.8 \mathrm{~mm}$ and $39.4 \mathrm{~mm}$, evaluated by Roos et al. (2006) from Couette analogy. This fairly influenced the results, as shown in previous paper with 
power law fluid (Estellé et al., 2008b), in particular for shear rate higher than $10 \mathrm{~s}^{-1}$. With helical ribbon, we have considered the virtual radius of the probe obtained by Roos and coworkers (2006). Actually, the use of the real radius leads to an error in calculated shear stress. This means that the fluid is mainly sheared at the inner periphery of the helical ribbon as the virtual radius is closed to the inner radius of this geometry. The averaged value of consistency and flow index behaviour we obtain from the mixing flow curves, are respectively $21.6 \mathrm{~Pa} . \mathrm{s}^{\mathrm{n}}$ and 0.34. This agrees well with the parameter values evaluated by Roos et al. (2006), respectively $21{\mathrm{~Pa} . \mathrm{s}^{\mathrm{n}}}^{\mathrm{a}}$ and 0.37 . Moreover, figure 4 proves the independency of the mixing probe morphology on the rheological behaviour of the fluid. As the radius ratio is different with the three mixing geometries, the shear rate range obtained is also quite different, in particular at low shear rate: higher the radius ratio is, lower the shear rate range. A comparable result was observed by Estellé et al (2008b) with Newtonian material. It worth nothing that comparison of equation (1) and (2) shows here again that the fluid is always fully sheared, as expected, due to its rheological behaviour.

\section{.4. Conclusions}

The feasibility of using a simplified procedure for computing the shear flow curve of mixing systems was tested. This was performed with Newtonian and non-Newtonian shear-thinning fluids. The influence of mixing impeller geometry was also investigated. It was shown that the procedure allows evaluating the appropriate rheological behaviour of the tested fluid, independently of the used mixing system. The constitutive parameters of Newtonian and power law models were determined for several fluids and were found to be close to the literature values. Moreover, it was shown that a priori assumption of rheological behaviour of fluid is not required. As well, the inner virtual radius calculation with mixing impeller is avoided, when the fluid is sheared along a surface close to a cylindrical one. This is of practical interest and time beneficial in both laboratory and industry.

Acknowledgements: The authors wish to thank J.P. Guillemin and U. Bolmstedt for providing the torque velocity data of mixing systems. This work is supported by the French National Agency of Research (ANR) under the project Physepat (05-NT05-443247).

\section{References}

Anne-Archard, D., Marouche, M., Boisson, H.C., (2006). Hydrodynamics and Metzner-Otto correlation in stirred vessels for yield stress fluids, Chem Eng J, 125, 15-24. 
Ait-Kadi, A., Marchal, P., Choplin, L., Chrissemant A-S., Bousmina, M., (2002). Quantitative analysis of mixertype rheometers using the Couette analogy, Canadian J Chem Eng, 80, 1166-1174.

Benkhelifa, H., Alvarez, G., Flick, D., (2008). Development of a scraper-rheometer for food applications: rheological calibration, J Food Eng, 85, 426-434.

Bousmina, M., Ait-Kadi, A., Faisant, J.B., (1999). Determination of shear rate and viscosity from batch mixer data, J Rheol, 43, 415-433.

Choplin, L., (2000). In situ rheological follow-up of food processes: application to emulsification and ice cream fabrication process, Proceedings of the $2^{\text {nd }}$ ISFRS, Zurich, Switzerland, 63-68.

Estellé, P., Lanos, C., Perrot, A., (2008). Processing the Couette viscometry using a Bingham approximation in shear rate calculation, J Non-Newtonian Fluid Mech. in press, doi:10.1016/j.jnnfm.2008.01.006.

Estellé, P., Lanos, C., Perrot, A., Amziane, S., (2008). Processing the vane shear flow data from Couette analogy, Appl Rheol, 18:3, 34037.

Guillemin, J.P., Menard, Y., Brunet, L., Bonnefoy, O., Thomas, G., (2008). Development of a new mixing rheometer for studying rheological behaviour of concentrated energetic suspensions, J Non-Newtonian Fluid Mech., 151,136-144.

Metzner, A.B., Otto, R.E., (1957). Agitation of non-Newtonian fluids, AICh J, 1, 3-10.

Roos, H., Bolmstedt, U., Axelsson, A., (2006). Evaluation of new methods and measuring systems for characterisation of flow behaviour of complex foods, Appl Rheol, 16, 19-25.

Steffe, J;F., (1992) Rheological methods in food process engineering, Freeman Press, Michigan, USA.

Thakur, R.K., Vial, C., Djelveh, G., Labbafi, M., (2004). Mixing of complex fluids with flat-bladed impellers: effect of impeller geometry and highly shear-thinning behaviour, Chem. Eng. Processing, 43, 1211-1222.

Wang., J-J., Feng, L-F., Gu, X-P., Wang, K., Hu, C-H., (2000). Power consumption of inner-outer helical ribbon impellers in viscous Newtonian and non-Newtonian fluids, Chem. Eng. Science, 55, 2339-2342. 


\section{Figure Captions}

Figure 1. Mixing geometries: (a) Rheo-FX developed by Guillemin et al. (2008) ; (b) paddles (left) and helical ribbon (right) used by Roos et al. (2006).

Figure 2. Shear flow curves of Newtonian fluids in both Couette (black symbols) and mixing system (open symbols) obtained from Bingham approximation in Couette geometry. The symbols refer to different Newtonian liquids: $\square$ Liquiflex ; $\bigcirc$ Urethane ; $\triangle 47$ V500.

Figure 3. Shear flow curves of energetic suspensions in mixing system obtained from Bingham approximation in Couette system.

Figure 4. Shear flow curves of fluid food - black symbols: data from Roos et al. (2006) ; open symbols: present work. 


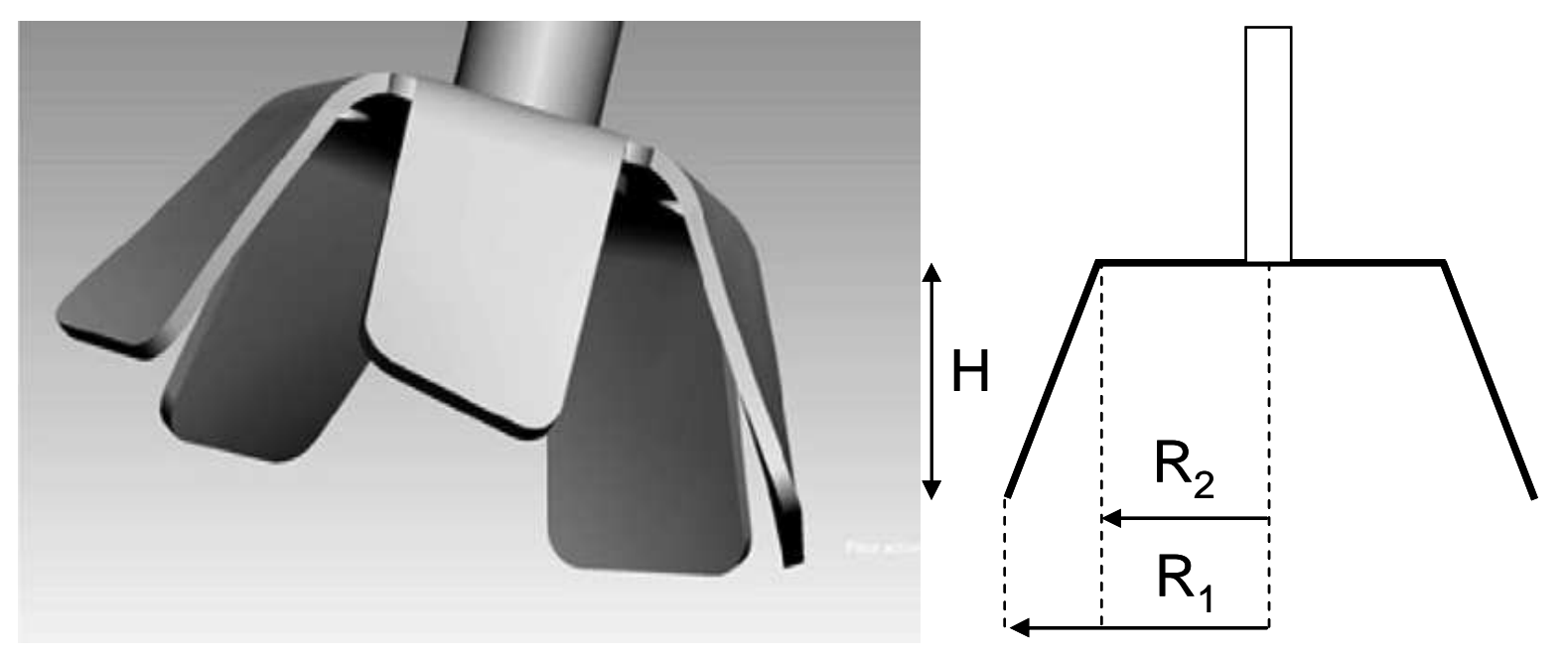

(a)

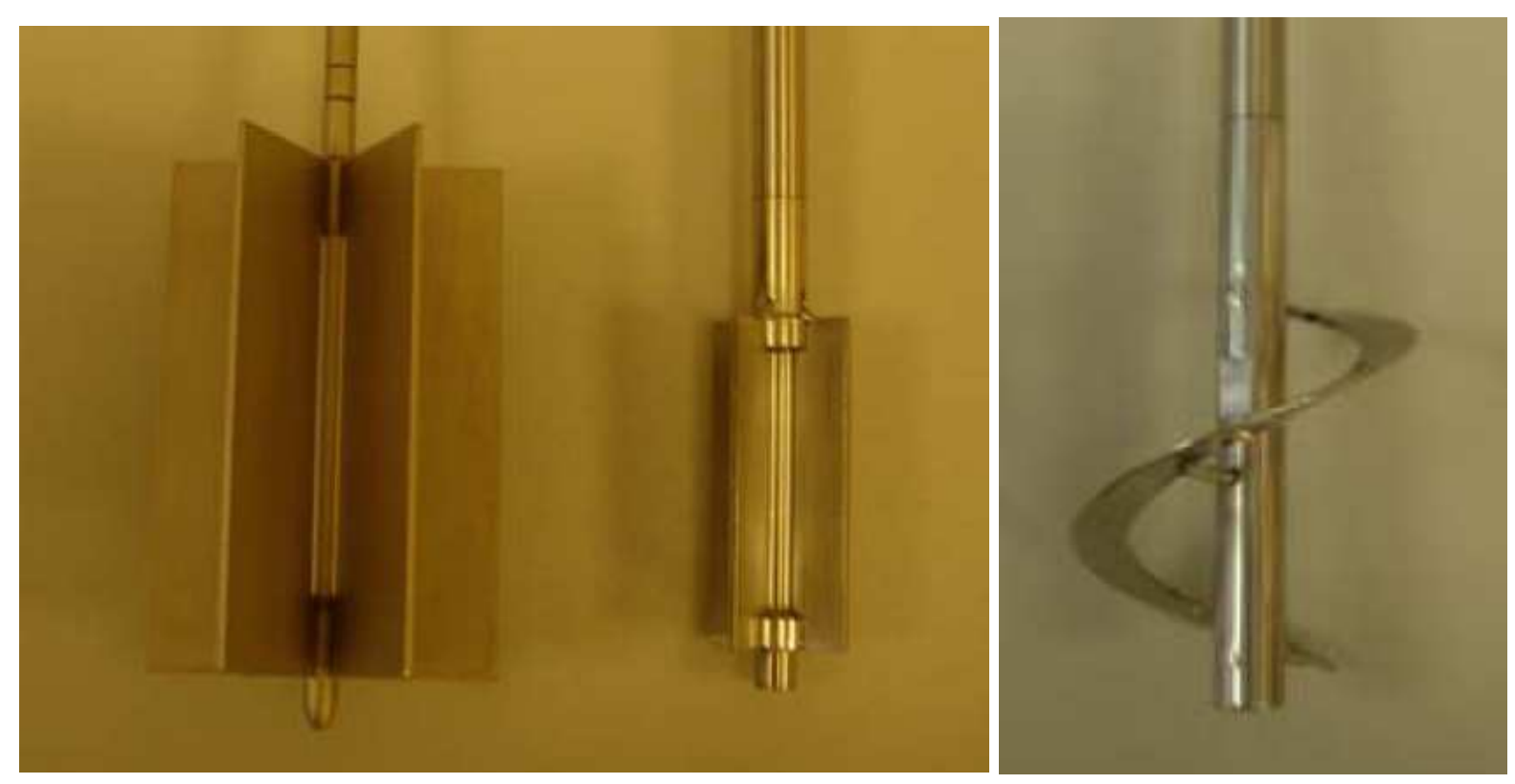

(b)

Figure 1. Mixing geometries: (a) left: Rheo-FX from Guillemin et al. (2008) - right: schematic side view ; (b) paddles (left) and helical ribbon (right) from Roos et al. (2006). 


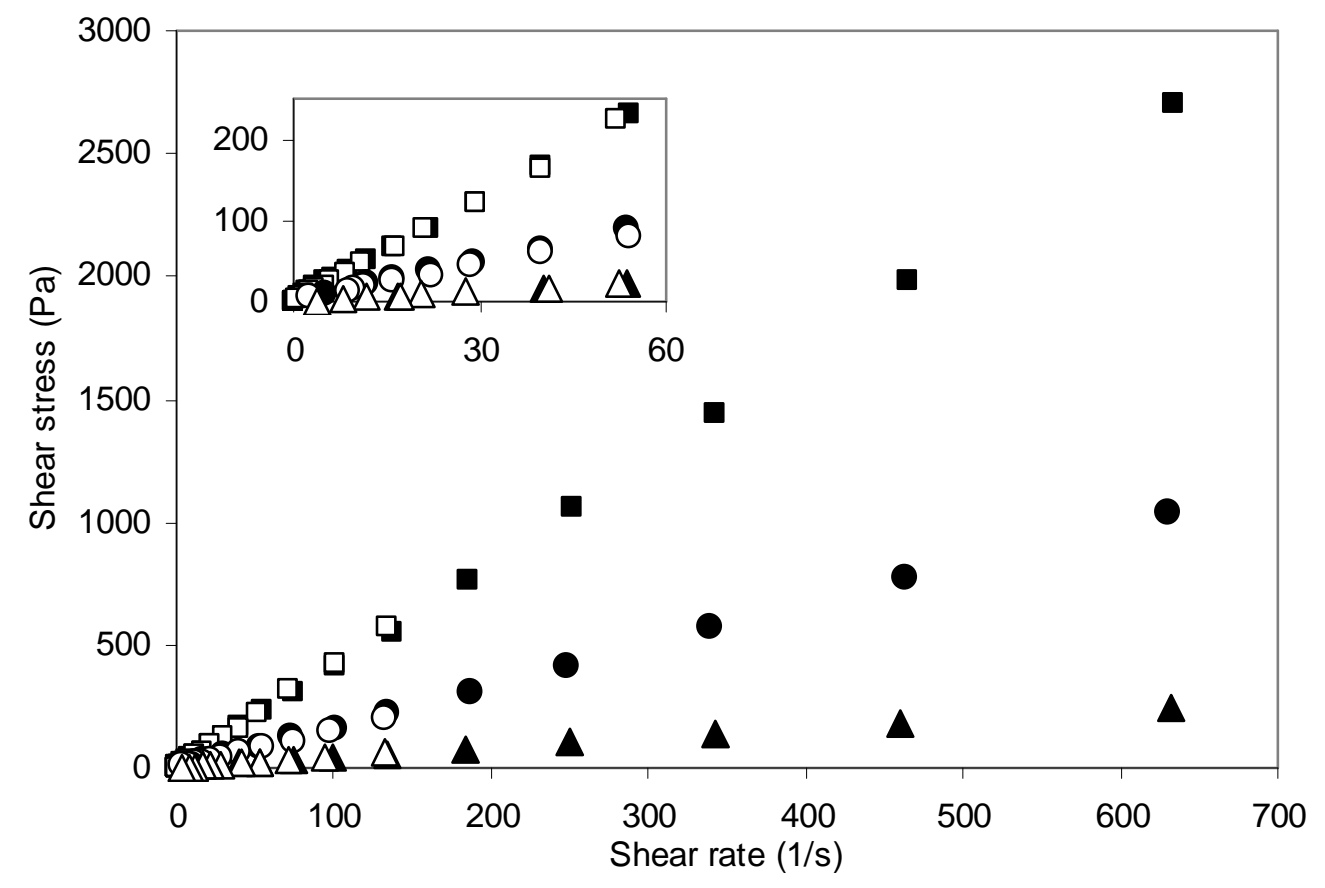

Figure 2. Shear flow curves of Newtonian fluids in both Couette (black symbols) and mixing systems (open symbols) obtained from Bingham approximation in Couette geometry. The symbols refer to different Newtonian liquids: $\square$ Liquiflex ; $\bigcirc$ Urethane ; $\triangle 47 V 500$. 


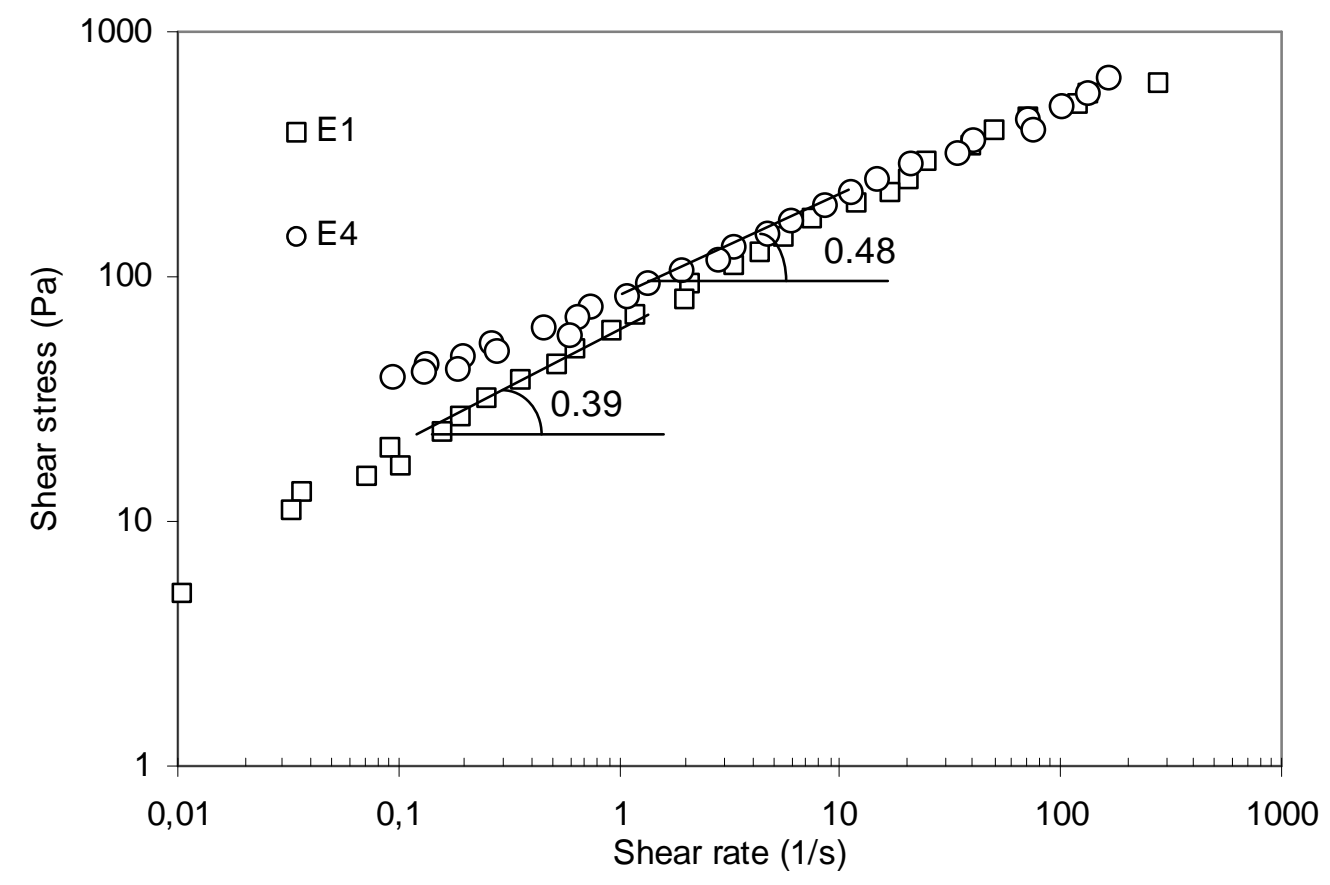

Figure 3. Shear flow curves of energetic suspensions in mixing system obtained from Bingham approximation in Couette system. 


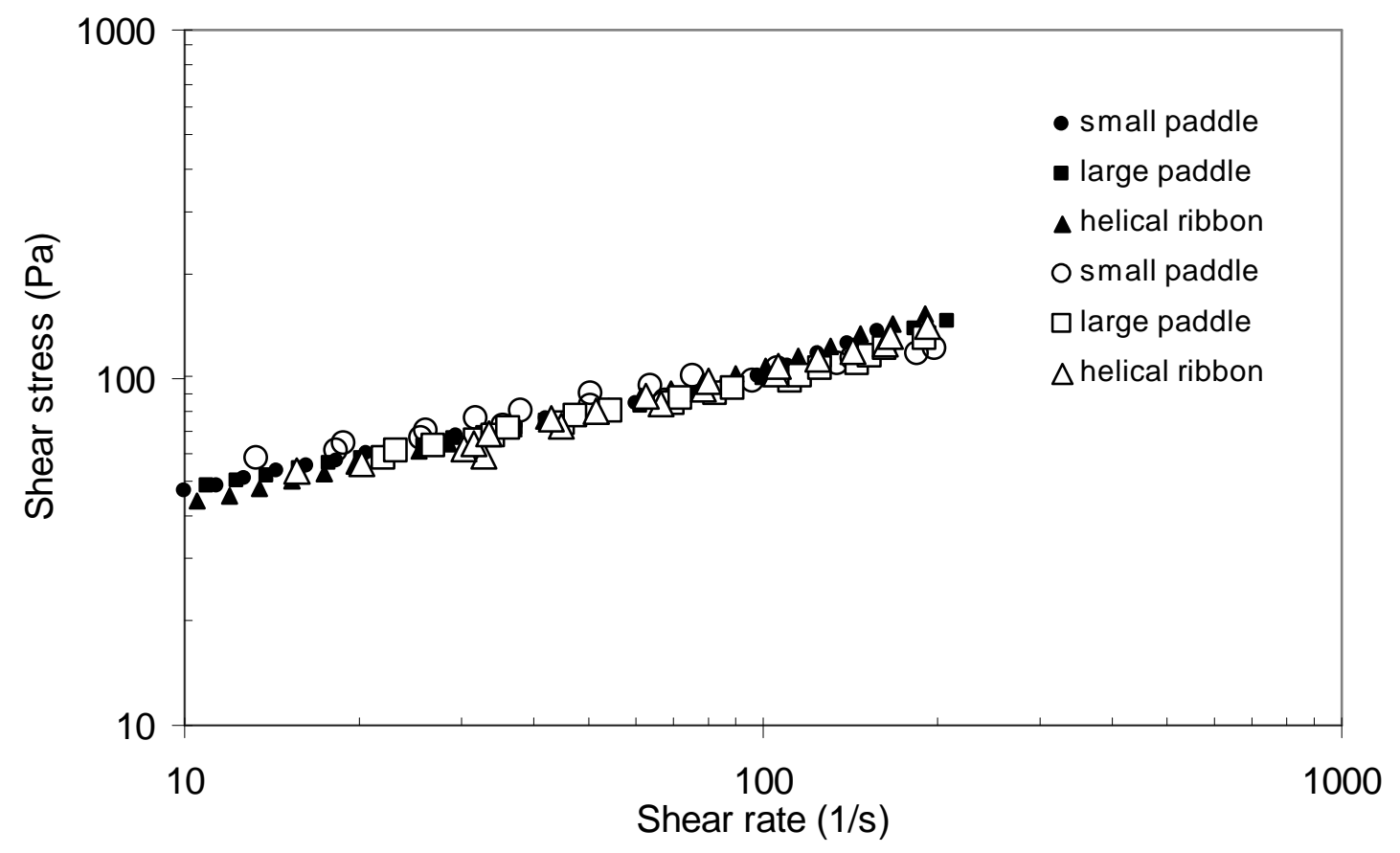

Figure 4. Shear flow curves of fluid food - black symbols: data from Roos et al. (2006) ; open symbols: present work. 
Table 1. Viscosity of Newtonian fluids obtained from regression of the shear flow curves in Couette and mixing systems.

\begin{tabular}{|l|c|c|c|c|}
\hline $\begin{array}{l}\text { Newtonian } \\
\text { fluid }\end{array}$ & $\begin{array}{c}\eta(\text { Pa.s) from Couette } \\
\text { geometry }\end{array}$ & $\begin{array}{c}\text { Deviation } \\
(\%)\end{array}$ & $\begin{array}{c}\eta(\text { Pa.s) from mixing } \\
\text { geometry }\end{array}$ & $\begin{array}{c}\text { Deviation } \\
(\%)\end{array}$ \\
\hline Liquiflex & 4.2 & 5.8 & 4.2 & 5.6 \\
\hline Urethan & 1.7 & 5.1 & 1.5 & 14 \\
\hline 47V500 & 0.4 & 6.6 & 0.46 & 8 \\
\hline
\end{tabular}

Table 2. Consistency and flow index behaviour of energetic suspensions obtained from regression of the shear flow curves in mixing system

\begin{tabular}{|l|c|c|c|c|}
\hline & $\mathrm{k}\left(\right.$ Pa.s $\left.^{\mathrm{n}}\right)$ & Deviation (\%) & $\mathrm{n}(-)$ & Deviation (\%) \\
\hline E1 & 58.3 & 4.8 & 0.47 & 10.9 \\
\hline E4 & 81.2 & 9.3 & 0.39 & 2.1 \\
\hline
\end{tabular}

